\title{
Ethical considerations concerning computers in medicine in the 1980 s
}

\author{
F T de Dombal University of Leeds
}

\section{Author's abstract}

The advent of information technology and computers in medicine two decades ago posed a new set of ethical problems. In recent years, these problems have been compounded by the increasing use of computers for supporting clinical decisions as well as administration and record keeping.

This presentation considers some of the problems which are raised by the use of computers to support clinical decisions, under the various headings of beneficence, non-maleficence, autonomy and justice. For each aspect the problems raised are described and the implications discussed.

\section{Introduction}

Computers have been used in medicine for about twenty years, and their use has duly been monitored by the World Medical Association for over a decade. Most recently in Venice in 1983, the World Medical Assembly published a series of detailed statements on the use of computers - which might reasonably be expected to be useful as guidelines to their implementation (1).

Unfortunately however, this is not entirely correct. The computer world moves very fast - and in the last 10-15 years the use of computers in medicine has both expanded dramatically and changed drastically. Thus, whilst the World Medical Association pronouncements mostly relate to data storage (and concentrate - quite logically - upon security and confidentiality of information) computers have now progressed far beyond simple data-storage devices.

In particular, the use of computers to provide decision-support in the practice of clinical medicine has been widely explored in the last twenty years. In the 1960s this posed little problem since none of the proposed systems proved to be at all effective! In the 1970 s small and more effective systems were devised but these raised only relatively minor ethical problems since they dealt with highly specific clinical situations - so that they could be (and were) regarded by doctors

\section{Key words}

Ethics; decision-making; computers. using them as 'just another special test'.

Nowadays however, with the rapid technical development of computers, with the explosion of $\vec{\omega}$

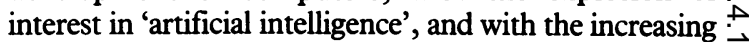
effectiveness of existing systems, the time has come to $\overparen{ }$ look again at their use in clinical medicine - and in o particular the ethical questions which they raise. In this presentation these considerations will be discussed in turn using as a framework the familiar principles of beneficence, non-maleficence, autonomy and justice.

\section{Beneficence}

Turning first to this aspect, it may seem simplistic $\stackrel{\infty}{\infty}$ assert that the computer system introduced to provie for decision-support in clinical medicine must beneficial. The point is however far from simplistic? since the vast majority of computer aids so far evaluated have failed completely to show any such

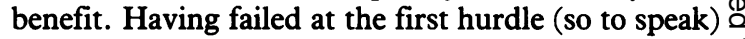
they need not be considered further. There are severe $\vec{\circ}$ and obvious ethical problems involved in the $\exists$ implementation of a system in medical practice which does not show benefit!

Sadly this simple point eluded computer persons in the 1960s. Waving printouts about like some kind of encyclical, computer enthusiasts of the 60 s promised $\frac{5}{3}$ the moon and offered systems that cost the earth but which actually achieved virtually nothing. More recently 0 however, it has become quite clear that the provision of computers to support clinical medical decisions can be 음 associated with substantial improvement in $>$ performance on the part of the doctor - together with a clear reduction in undesirable events and risk to the $N$ patient (2).

This argument is illustrated in Table $I$, which relates $N$ to one recent such study (3). From these data it is $\omega$ reasonable to argue that the adoption of a computeraided system to assist clinical decision-making has been 0 beneficial; and as such it is therefore also reasonable to $\Phi$ consider further the ethical questions raised by such $\stackrel{?}{?}$ systems and their use.

\section{Non-maleficence}

If computers are to be utilised to assist clinicians in $\stackrel{\mathbb{2}}{2}$ their decision-making role, two questions of non- 
TABLE 1

Summary of findings in recent Department of Health and Social Security (DHSS) Trial of computer-aided decision support-system for acute abdominal pain

Baseline

Trial Period

(4075 cases)

(12662 cases)

Initial diagnostic

accuracy

$45.6 \%$

$65.3 \%$

Post-investigation

diagnostic accuracy

$57.9 \%$

$74.2 \%$

$\%$ NSAP ${ }^{\star}$ patients admitted

from Accident/emergency

$40.9 \%$

$26.3 \%$

$\%$ NSAP patients who reattended

Accident/emergency

$7.4 \%$

$1.5 \%$

$\%$ NSAP patients operated on

$9.5 \%$

$5.6 \%$

Perforated appendicitis rate

$23.7 \%$

$11.6 \%$

Annual Negative

saving laparotomies

$\begin{array}{cc}- & 139 \mathrm{pa} \\ - & 3387 \mathrm{pa} \\ - & 871 \mathrm{pa}\end{array}$

Appendicitis

bednights

$871 \mathrm{pa}$

Bad management errors

$0.9 \%$

$0.2 \%$

Death

$1.20 \%$

$0.92 \%$

^ NSAP - Non-specific abdominal pain (not needing surgical treatment)

From: Adams I D, Chan M, Clifford P C et al (3). 
maleficence must be considered.

The first is an immediate problem. It can readily be asserted that the use of such systems must not bring harm to patients. However, the computer (unless suitably programmed) has no concept of error and cannot quantify the harm caused by its mistakes. Moreover, at present, attempts to quantify 'harm' have proved elusive - even though a variety of techniques have been put forward. Any computer program which attempts to balance in mathematical fashion (currently fallible) estimations of harm must be gravely suspect and this is a vital point since it implies that for the foreseeable future the final clinical decision must rest with the doctor and the patient, and not the computer. This point in turn has quite fundamental implications concerning the future role of computers in decisionsupport systems.

The second issue is more long term. It is all very well to say that the doctor should make decisions, and to demonstrate that the doctor is more effective in doing so whilst aided by a computer. But (and this specially applies to doctors in training grades) one needs to be quite certain that when the computer stimulus is withdrawn, or when a different area of medicine is addressed, the doctor's own innate and highly trained ability to make clinical and other judgements has not been eroded by reliance on a machine.

In the medium term a number of studies $(3,4)$ have provided relatively reassuring evidence suggesting that with current systems (such as that represented in Table I) this type of erosion is not a problem. However, further studies need to be carried out particularly in the longer term before such an assertion can be made with any confidence.

\section{Autonomy}

Perhaps the most interesting of all the issues raised by the application of computers to decision-support, concerns the autonomy of the patient and that of the doctor.

As regards the patient, it should be axiomatic that the use of a computer for decision-support must not contravene the patient's autonomy. Some issues have been addressed elsewhere in this discussion, such as that of confidentiality; and of course it is well recognised by recent pronouncements (5) that any use of medical databanks should in no way undermine the patient's right to privacy.

A further aspect which is worth mentioning when considering patients' autonomy concerns the attitude of the patient to the use of a computer system. Actually a number of studies on this point (6) have indicated clearly that in the main patients are not bothered at all by such usage provide any final decision rests with them and their doctor. Indeed, one famous study where computers actually interviewed patients gave rise to the (quite astonishing) result that patients questioned after the trial considered the computer to be more sympathetic and more bothered about their problem than the doctor (7)!

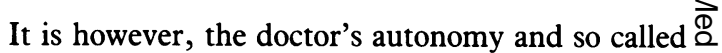
'clinical freedom' which has given rise to most $\underset{+}{+}$ discussion. Indeed, the utilisation of computers to aid clinical decisions must raise the whole issue of clinical $\stackrel{?}{?}$ freedom - what it means, what it is worth, and whether $\overrightarrow{\vec{F}}$ it should be maintained or abandoned.

The latter view is taken by Hampton - 'Clinical freedom is dead ... and we need not mourn its $\frac{\bar{\sigma}}{\overline{\hat{n}}}$. passing. It was . . . at worst a cloak for incompetence' $\overparen{\nabla}$ (8). This editorial in the British Medical fournal 2 produced a lively discussion - much of it agreeing with Hampton.

However, a different point of view has been well expressed by Barnett (9) who writes:

'In the real world it is necessary that the doctor not only understands the statistical relations of signs and $\vec{\omega}$ symptoms to the various possible diseases but also has $\dot{A}$ the wisdom and common sense that derive from the $\vec{v}$ understanding and experience of everyday human 0

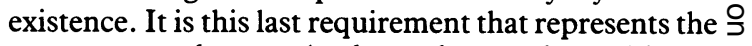
greatest weakness (and perhaps the ultimate limitation) of computer technology in dealing in any comprehensive fashion with the problem of clinical diagnosis'.

In practice, two issues are raised. First, is the doctor $\vec{\varphi}$ free to disagree with the prediction of the computero $\stackrel{\infty}{\circ}$ or more properly should he be free to do so? In practice all indications seem to suggest that he should be free to disagree and that even the most advanced artificianl intelligence system should be used as a 'special investigation', overruled by the doctor if the doctor

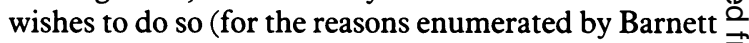
(9)). It might well be argued however that a need to $\overrightarrow{\bar{O}}$ consider the computer prediction and comment could be viewed as extending the rationality component of autonomy.

This implies however a further point - small but important - which is that (like any other special test) the doctor needs to know what the computer's 3 predictive accuracy is, in terms of sensitivity and specificity and so on for a particular disease. All too 윽 often in respect of many special investigations this information is simply not available to doctors - and it should be.

The critical question therefore seems to be - to what extent should this development (computer support for $N$ clinical decision-making) actually restrict the doctor's $N$ autonomy. To argue that it should not do so at all implies an absolute belief in clinical freedom, $\omega$ including the ability of every doctor to do exactly what he or she wishes; and whilst one accepts the limitations of computers perhaps it is wise also to accept some limitation (as Hampton suggests) on doctors' clinical freedom as well.

For it is worth remarking that 'clinical freedom' is $\underset{\mathbb{D}}{\mathbb{D}}$ not an inherent right, but is granted to the doctor both $\stackrel{\odot}{\mathbb{1}}$ by society (which confers the right to practise $\stackrel{2}{2}$ medicine) and by the patient (in the act of seeking? 
help). There is moreover an implicit assumption in both cases that such freedom will be used as effectively as possible and in the best interests of the patient.

One possible solution to this problem comes from the world of aviation, for in fact the airlines have already met this problem and dealt with it. One clearly would not wish to reduce the freedom of the pilot to make judgements and fly an aircraft. However, the fact remains that 80 per cent of accidents in the air are due to 'simple human errors', often of a quite ludicrous nature (such as the pilot who circled for hours to use up fuel because of a minor problem - and then ran out of fuel before reaching an airport!) which computer support systems tend to minimise.

The airlines have dealt with the situation in two ways. First they have designed their computer-aided, decision-support systems with very heavy emphasis upon the user rather than the system. Second, they have created what is referred to as an 'electronic cocoon'. This is a concept which implies a broad framework of pre-agreed 'reasonable' performance and action, within which the pilot can behave at will. However, once certain boundaries (agreed in advance by all concerned to represent undesirable performance) are crossed, then the fact is drawn to the pilot's attention and he is urgently and strenuously advised to adopt an alternative course of action.

It should not be beyond the wit of man to devise some similar arrangement for clinical medicine whereby (within a broad framework) the decisionsupport system is totally subservient to the doctor. Nevertheless once limits of tolerance (agreed by a wide section of the medical community in advance), are exceeded, the role of the machine would be less subservient. This need not imply a dominant role for the computer - for example, the computer might restrict its advice to the doctor to that of suggesting consultation with a senior colleague - but it does imply that once pre-specified and widely agreed limitations are exceeded, the doctor is not allowed to proceed entirely unhindered.

\section{Justice}

Several interesting and important questions are raised under this latter heading. The most frequent and obvious is quite simple - if one uses a computer and the computer is wrong who is to blame? This provokes much argument (a great deal of it extremely illinformed) which is not surprising, since the question itself is hardly a simple one.

The answer clearly is 'it depends'. It depends on the role of the computer in that particular system and it depends on what went wrong. For example, if a demonstrable technical error in programming has led to a false prediction (given accurate data) then the programmer is at fault. On the other hand if the programming is correct but the computer was fed with erroneous or inadequate symptoms and signs (for example if the computer failed to diagnose ovarian cyst because the doctor keyed in 'male' by mistake), then responsibility clearly rests with the doctor.

However, it isn't quite as simple as that - and to understand the problem more clearly we need to define more clearly what is meant by an 'expert system'. In some such systems the computer compares a new patient's data with data from a large series of patients with similar clinical diseases. There is relatively little problem here. But other systems rely not upon real-life data, but the opinions of an 'expert' - and as the adage has it '. . . who's to say what experts make the rules; experts to some, to others may be fools!'. Thus if a widely distributed 'expert system' using rules-ofthumb provided by $\mathrm{Dr} \mathrm{X}$ is subsequently shown to be (a) dangerous, (b) foolish, and (c) at variance with current consensus opinion, surely justice demands that Dr X, rather than the programmer or the user, is responsible for any harm caused.

There are however two corollaries of such an argument which are central to this theme. First, areas of responsibility must be clearly laid down in advance. If the doctor is to be responsible then this must be specified and the doctor must signify that this is acceptable before using the system. Second, there must be a sound clinical basis for the prediction of the computer-aided system, a comprehensive 'track record' of prior performance, and the doctor must know what this is. Computer systems, like all high technology, should be thoroughly evaluated before entry into service - though sadly much technology has already entered health-care service without proper evaluation.

An interesting alternative to this theme is one which has already emerged - what happens if the doctor is wrong but has ignored or overridden a (correct) computer prediction? Again the problem is that there are different circumstances. If the doctor failed to use the computer at all, then perhaps the doctor should be regarded as being to some extent at fault - just as if the doctor had failed to diagnose a fracture by refusing to perform an x-ray. However, if the doctor has used a computer-aided system correctly and (for specific reasons) decided to override its prediction then justice would suggest that the argument of Barnett (see above) should come into play though perhaps the onus is then upon the doctor to demonstrate the decision made was a reasoned one.

This is particularly relevant in the UK where the position seems to be that if the doctor has done what a group of his fellow medical practitioners, (skilled and experienced, respected and respectable) would themselves have done, then he cannot be held to be negligent.

An interesting and relevant contribution to this topic was recently published in the medico-legal columns of the British Medical fournal (10). In this assessment Dyer draws a distinction (in discussing product liability) between different forms of liability. Pointing out that a plaintiff must prove that a product is defective, that he/she suffered damage, and that there 
is a causal relation, Dyer emphasises that a product is to be considered defective (according to the 1986 Consumer Protection Bill) 'if the safety of the product is not such as persons generally are entitled to expect'.

This seems inherently sensible. On the one hand strict liability poses problems: it would imply that, any side-effect (of products or drugs) implies liability (for example, any drug may shorten life). On the other hand the problem of liability also implies a duty (as we have already discussed) to specify very carefully how much help a doctor can expect. It implies, in other words, an obligation (a) to evaluate systems fully, (b) to publish the results of such evaluation as widely as possible, and (c) to ensure - as far as possible - that these results are known to the user.

\section{Counter-arguments}

At a discussion meeting concerning ethical problems in gastroenterology held at Windsor Castle by the World Organisation of Gastroenterology, several speakers emphasised the importance (when any medical innovation is discussed) of considering the counter-arguments and problems associated with its use. Actually, many of the counter-arguments such as possible dehumanisation of the diagnostic process and loss of decision-making capability by doctors have already been considered earlier but some further problems remain and should be considered.

\section{CONFIDENTIALITY}

Some authorities (5) consider this to be the most important problem of all. Medical data is often very 'sensitive' and there is a clear need for computersystem designers to be aware of this special requirement.

In practice, it is possible to be thoroughly hypocritical about this. Conventional medical records by and large are not very secure - and it is only too easy to gain access to the data within them under current hospital conditions. By comparison many computer systems dealing with medical data are more secure than Fort Knox.

Nevertheless, it is important to recognise that the security problems involving computers are of a different type. It is possible where computerised medical records are involved to gain access to vast amounts of medical data at a stroke; and moreover data which could be of use in certain situations outside medicine (for example to the police, or insurance companies etc).

All of this implies a need for computerised medical data to be especially secure; and clearly in the UK there is a need for medical data systems to conform with the regulations of the Data Protection Act. However, the need is greater than this. Computer systems will only be secure provided those who operate them regard themselves to be bound by the same considerations of confidentiality as those directly rsponsible for the medical management of the patient.

\section{THE 'PINK FLOYD SYNDROME'}

An interesting variant to the problems of loss of $\overrightarrow{\overline{\bar{t}}}$. decision-making capability is a syndrome which has? been referred to as the 'Pink Floyd Syndrome'. This $\Rightarrow$ refers to the first line of a popular song by the group $\stackrel{?}{+}$ 'Pink Floyd', in which - as The Times somewhat? sniffily observed - a group of school-children utter a $\frac{\bar{F}}{\bar{D}}$ sentiment, the inaccurately expressed claim of which is $\vec{\sigma}$ manifestly untrue . . . 'we don't need no education'! $\stackrel{1}{2}$ The 'Pink Floyd' syndrome thus describes an attitude $\%$ on the part of some doctors who feel that their hard- $\vec{\circ}$ won expertise is challenged rather than complemented by a machine system, and who are reluctant to utilise it $\vec{\omega}$ in the belief that it belittles their academic? achievement.

Clearly this is a problem which must be taken into account; and perhaps the most obvious method of $\omega$ doing so is to increase the role of automated systems in medical education - both by using them to assist the $\vec{c}$ education process itself and also by instructing $ᄋ$ prospective medical practitioners about the uses and abuses of computer systems in medicine.

\section{MALICE}

Computer people often have a view of the world which $\stackrel{\mathbb{\Phi}}{\leftrightarrows}$ is both condescending and naive. They tend to design $\vec{\bullet}$ 'foolproof' systems, but as Arthur C Clarke has pointed $\stackrel{\infty}{-\infty}$ out it is easy to design a foolproof system but difficut to design one which is malice-proof. This is important point. Who would have believed a decade or two ago the developments in computer crime, in the socalled 'hacker' explosion - with young people 'tappingin' to systems ranging from commercial firms' ordering systems to defence systems.

This implies a need for scrutiny - constant scrutiny - of existing systems. Though it should clearly not be used as an excuse in itself for inertia, the problem should be recognised and monitored.

\section{Conclusion}

It is thus apparent that the advent of computers in clinical medicine, and particularly their use in providing decision-support, raises a number of $ᄋ$ interesting ethical questions. For clarity these have been set out under various headings but perhaps the most important point is a more general one - and one $\stackrel{\bar{N}}{\mathrm{~N}}$ that has often been raised by Dunstan (11).

For surely we need to hear less about rights and more $N$ about duties and obligations. We need to hear less $\underset{\mathrm{C}}{\mathcal{N}}$ about the rights of doctors to do what they like in the 0 name of 'clinical freedom', and more about doctors'

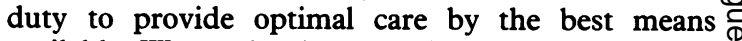
available. We need to hear less from computer people $\stackrel{\mathscr{S}}{+}$ about the iniquity of medical mumbo jumbo and more 0 about their own duty to design systems which fit into the existing framework of medical management.

Above all, we need to hear more from both medical $\frac{\Omega}{\square}$ and computer scientists about mutual obligations to $\bar{\sigma}$ pool their talents in order to provide better medical 
care for the individual patient and to conserve as best they can the increasingly scarce resources available.

F T de Dombal MA MD FRCS is Reader in Clinical Information Science, University of Leeds.

(See also: Computer-aided medical ethics, page 185.)

\section{References}

(1) World Medical Assembly (35th): Code of Ethics on human experimentation, cited in Handbook of medical ethics. London: British Medical Association, 1984: 77 et seq.

(2) de Dombal F T, Leaper D J, Horrocks J C, Staniland J R, McCann A P. Human and computer-aided diagnosis of abdominal pain: A further report with emphasis on the performance of clinicians. British medical journal 1974; 1: 376.

(3) Adams A I, Chan M, Clifford P C et al. Computer-aided diagnosis of acute abdominal pain: a multi-centre study. British medical journal 1986; 293; 300.
(4) McAdam W A F. Computer-aided diagnosis of acute abdominal pain in a District General Hospital. Report to DHSS, 1978.

(5) Macara A W. Confidentiality - a decrepit concept? Fournal of the Royal Society of Medicine 1984; 77: 577.

(6) Horrocks J C, de Dombal F T. Computer-aided diagnosis of dyspepsia. American journal of digestive disorders 1975; 20: 397.

(7) Knill-Jones R P. A formal approach to symptoms in dyspepsia. Clinics in gastroenterology. 1985; 14, 3: 517.

(8) Hampton J R. The end of clinical freedom. British medical journal 1983; 287: 1237.

(9) Barnett G O. The computer and clinical judgment. New England journal of medicine 1982; 307, 8: 493.

(10) Dyer C. Product liability comes closer. British medical journal 1986; 293: 1489.

(11) Dunstan G R. Closing remarks at a workshop meeting of the World Organisation of Gastroenterology held at St George's House, Windsor Castle, 1986 Apr 29-May 2. Published in de Dombal F T, Holt P R, Sidorov J J, eds. Ethics in gastroenterology. Leeds University Printing Service, 1986: 49. 